\title{
A meta-study investigating the sources of protest behaviour in stated preference surveys
}

Mørkbak, Morten Raun; Olsen, Søren Bøye; Meyerhoff, Jürgen

Publication date:

2010

Document version

Peer reviewed version

Citation for published version (APA):

Mørkbak, M. R., Olsen, S. B., \& Meyerhoff, J. (2010). A meta-study investigating the sources of protest

behaviour in stated preference surveys. Paper presented at World Congress of Environmental and Resource Economists 2010, Montreal, Canada. http://www.wcere2010.org/index.htm 


\title{
A meta-study investigating the sources of protest behaviour in stated preference surveys
}

\author{
Morten Raun Mørkbak ${ }^{1}$, Søren Bøye Olsen², Jürgen Meyerhoff ${ }^{3}$
}

\begin{abstract}
It is well known that some percentage of respondents participating in Stated Preference surveys will not give responses which reflect their true preferences. One reason is protest behaviour. If the distribution of protest responses is not independent of respondent demographics, the elicitation method, the question format, etc., then simply expelling protesters from surveys will lead to sample selection issues. Furthermore, WTP estimates will not be comparable across surveys. This paper seeks to explore potential causes of protest behaviour through a meta-study based on data from 10 different surveys. The objective of the study is to examine the effect of respondent specific variables as well as survey specific variables on protest behaviour. Our results suggest that some of the differences in WTP typically observed between different demographic groups, different elicitation formats and different question formats might actually be attributed to inherent differences in the propensity to protest. Our results indicate that the propensity for respondents to exhibit protest behaviour when asked a stated preference type valuation question depends on a number of specific factors, respondent specific as well as survey specific.
\end{abstract}

\section{Keywords}

Protest behaviour, stated preferences, survey design, willingness to pay

\section{JEL Classification}

C93, D03, D60, Q51

\footnotetext{
${ }^{1}$ University of Copenhagen, Institute of Food and Resource Economics, Rolighedsvej 25, 1958 Frederiksberg C, Denmark, mm@foi.dk

${ }^{2}$ University of Copenhagen, Institute of Food and Resource Economics, Rolighedsvej 25, 1958 Frederiksberg C, Denmark, sobo@life.ku.dk

${ }^{3}$ Technische Universität Berlin, Institute for Landscape Architecture and Environmental Planning, Strasse des 17. Juni 145, 10623 Berlin, Germany, meyerhoff@imup.tu-berlin.de
} 


\section{Introduction}

It is agreed in the literature on stated preference methods that some respondents do not state their true value for the good in question. Therefore, in many studies it is checked whether respondents stated a protest answer, i.e. that respondents reject (protest against) some aspect of the constructed market scenario. If protesting occurs, stated preference methods might fail to determine the correct economic value of the good in question.

Boyle (2003) suggests that there are three main reasons why respondents might not express their true value. The first is that some people may not understand what they are asked to do in the survey, but they answer the valuation question anyway. The second reason is that respondents might act strategically. They hope that the change in the provision of the good will be paid by other people so that they do not have to reveal their true preferences. Thirdly, respondents may protest against some component of the valuation scenario or, as Mitchell \& Carson $(1989,166)$ put it, these respondents "refuse to play the game" economists want them to play.

The usual way of differentiating between a true zero WTP and a protest response is to present respondents who are unwilling to pay with a set of debriefing questions. Based on the answers to these questions, researchers decide whether each zero WTP corresponds to the economic concept of value or whether respondents are protesting against the valuation scenario. Meyerhoff \& Liebe (2008) find that some of those who are willing to pay also hold protest beliefs. This finding is in contrast to the common assumption that only respondents who are not willing to pay hold protest beliefs and strongly supports Jorgensen and Syme (2000) who argue that censoring of protesters is unjustified. Nevertheless, the typical way of dealing with protest responses, i.e., protesters among those who are not willing to pay, in practice is to delete them from the sample (Morrison et al. 2000). In the course of the debate about protest responses, a variety of reasons why respondents might protest have been suggested. A number of possible reasons have been mentioned in the literature: Dissension with specific aspects of the study such as for instance the payment vehicle; the policy context; ethical beliefs indicated by for example lexicographic preferences; misunderstandings or lack of information; fairness aspects; the type of good; institutional settings of the survey; and demographic characteristics of the respondent (Boyle 2003; Jorgensen et al. 1999; Jorgensen et al. 2001; Meyerhoff \& Liebe 2006; Mogas et al. 2005; Morrison et al. 2000; Strazzera et al. 2003; Söderquist 1998)

As shown above, the issues of different respondent and survey specific aspects potentially affecting protest behaviour have been mentioned in the existing literature, but to the authors' best knowledge many of these aspects have yet to be empirically investigated. For instance, Meyerhoff \& Liebe (2008) stress the need for future studies to investigate whether protest beliefs and protest responses differ when the constructed market settings vary in terms of, e.g., using taxes as a payment vehicle and/or the dichotomous choice as a payment question format in $\mathrm{CV}$. 
The present paper brings a novel contribution to the literature by exploring and explaining potential causes of protest behaviour in Stated Preference (SP) surveys through a meta-study based on data from 10 different SP surveys. More specifically, the objective of the study is to indentify respondent specific variables which vary for each single respondent, as well as survey specific variables which vary only across surveys. This distinction between respondent specific variables and survey specific variables is quite important for one major reason: While we would typically aim to minimize protest behaviour in any SP survey, the respondent specific variables offer only very limited options for the researcher for actively pursuing this objective. However, adjusting the survey according to the survey specific variables is to a much larger extent within the grasp of the researcher. In other terms, if the survey specific variables significantly affect the probability of observing protest behaviour, the researcher can actively adjust the overall design of the survey in order to reduce this probability.

The results of the meta-study show that a number of both respondent specific variables as well as survey specific variables have a significant influence on the likelihood of observing protest behaviour in SP surveys. Age and parental status affected the probability of observing a protest response in a positive way, while household income and knowledge of the good had a negative effect. With respect to the survey specific variables, characteristics like the good being a market good, using CE instead of CVM, well described scenarios, using tax as payment vehicle, and inclusion of a cheap talk script reduced the likelihood of a protest response, while aspects like using open ended questions and opt-out reminders increase the probability of obtaining a protest response. The reader should though bear in mind that the results to some extent are preliminary and that we plan to extend the database in order to get more variation with respect to the survey specific variables Nevertheless, the results suggest some potentially important practical bearings and guidance for researchers wishing to reduce the number of protesters (and thus increasing the effective sample size) in future studies.

The paper is organized as follows. Section 2 briefly describes the data used in the survey as well as the method applied in the analysis. In section 3 the results are presented. Finally we discuss and conclude in section 4.

\section{Method and data description}

\subsection{Dataset}

The dataset used in the analysis is based on data from 10 different stated preference surveys as described in table 1 . The surveys cover a range of different topics dealing with market as well as non-market goods, CEs as well as CVMs, open ended (OE) as well as dichotomous choice (DC) and payment card (PC) approaches, and different modes of sampling and different ways of formulating the valuation questions are represented. Within each survey there are also some variation due to different experimental splits used, which in total provides us with 34 differing data sets. The 10 surveys are described below in table 1 with respect to applied method, number of respondents, identified share of protesters, and a short description of the topic of the survey. 
Table 1. Surveys included in the meta-study

\begin{tabular}{|c|c|c|c|c|}
\hline No. & Author & Method & $\begin{array}{l}\text { \# Respondents } \\
\text { (\% Protesters) }\end{array}$ & Topic of survey \\
\hline 1 & $\begin{array}{l}\text { Mørkbak et al. } \\
\text { (2009) }\end{array}$ & $\mathrm{CE}$ & $\begin{array}{l}3878 \\
(3.1 \%)\end{array}$ & $\begin{array}{l}\text { Consumer preferences for food } \\
\text { safety in chicken fillets with focus } \\
\text { on Salmonella and Campylobacter. }\end{array}$ \\
\hline 2 & $\begin{array}{l}\text { Mørkbak \& } \\
\text { Nordström (2009) }\end{array}$ & $\mathrm{CE}$ & $\begin{array}{l}8208 \\
(8.4 \%)\end{array}$ & $\begin{array}{l}\text { Consumer preferences for food } \\
\text { safety in whole fresh chicken with } \\
\text { with focus on Campylobacter and } \\
\text { outdoor produce. }\end{array}$ \\
\hline 3 & Olsen et al. (2005) & $\begin{array}{l}\text { CVM (OE } \\
\text { and DC) } \\
\text { and } \mathrm{CE}\end{array}$ & $\begin{array}{l}4361 \\
(12.7 \%)\end{array}$ & $\begin{array}{l}\text { Preferences for location of new } \\
\text { motorways through open } \\
\text { landscapes/nature areas. }\end{array}$ \\
\hline 4 & $\begin{array}{l}\text { Jensen et al. } \\
\text { (2010) }\end{array}$ & $\mathrm{CE}$ & $\begin{array}{l}954 \\
(8.1 \%)\end{array}$ & $\begin{array}{l}\text { German anglers preferences for } \\
\text { recreational angling in Denmark }\end{array}$ \\
\hline 5 & $\begin{array}{l}\text { Ladenburg \& } \\
\text { Olsen (2009) }\end{array}$ & $\mathrm{CE}$ & $\begin{array}{l}585 \\
(11.8 \%)\end{array}$ & $\begin{array}{l}\text { Local citizens preferences for re- } \\
\text { establishment of a stream in a green } \\
\text { park area in Greater Copenhagen }\end{array}$ \\
\hline 6 & $\begin{array}{l}\text { Tranberg et al. } \\
\text { (2005) }\end{array}$ & $\begin{array}{l}\text { CVM } \\
(\mathrm{OE})\end{array}$ & $\begin{array}{l}873 \\
(39.9 \%)\end{array}$ & $\begin{array}{l}\text { House owners' preferences for } \\
\text { increasing the protection against } \\
\text { flooding along the west coast of } \\
\text { Jutland }\end{array}$ \\
\hline 7 & Hartje et al. (2002) & $\begin{array}{l}\text { CVM } \\
(\mathrm{PC})\end{array}$ & $\begin{array}{l}1387 \\
(55.7 \%)\end{array}$ & $\begin{array}{l}\text { Preferences for protecting the } \\
\text { Wadden Sea at the North Sea against } \\
\text { rising sea level }\end{array}$ \\
\hline 8 & $\begin{array}{l}\text { Meyerhoff \& } \\
\text { Dehnhardt (2007) }\end{array}$ & $\begin{array}{l}\text { CVM } \\
(\mathrm{PC})\end{array}$ & $\begin{array}{l}1284 \\
(19.6 \%)\end{array}$ & $\begin{array}{l}\text { Preferences for extending the } \\
\text { riparian wetlands along the River } \\
\text { Elbe }\end{array}$ \\
\hline 9 & $\begin{array}{l}\text { Christoffersen } \\
\text { (2006) }\end{array}$ & $\begin{array}{l}\text { CVM } \\
\text { (DC) }\end{array}$ & $\begin{array}{l}360 \\
(34.4 \%)\end{array}$ & $\begin{array}{l}\text { Local citizens preferences re- } \\
\text { establishing a marshland area on the } \\
\text { island of Rømø }\end{array}$ \\
\hline 10 & $\begin{array}{l}\text { Nielsen et al. } \\
\text { (2007) }\end{array}$ & $\mathrm{CE}$ & $\begin{array}{l}159 \\
(6.9 \%)\end{array}$ & $\begin{array}{l}\text { Preferences for the visual } \\
\text { appearance of forests in relation to } \\
\text { the introduction of near-natural } \\
\text { forest management regimes }\end{array}$ \\
\hline
\end{tabular}

From each of these datasets, we have extracted the information corresponding to the variables described in table 2 . Subsequently, the datasets have been merged into a single large dataset forming the basis for the empirical analysis in section 4 . 


\subsection{Econometric model}

Common for all the surveys in table 1 is that debriefing questions concerning potential protest bidding have been asked. Thus, in all the surveys protest bidders have been identified. As the purpose of this paper is to explore potential causes of protest behaviour, this protest bidder identification serves as a suitable measure for the dependent variable which we seek to explain ${ }^{1}$. Due to the binary nature of this identification of protest behaviour (either a respondent exhibits protest behaviour or not), a probit model is used in the econometric analysis to identify explanatory variables for protest behaviour. The binary probit model is an index model specified as the conditional probability that a binary response variable will take the value one:

$$
P(y=1 \mid x)=G\left(x^{\prime} \beta\right) \equiv p(x) \quad \in \mathbf{\coprod}_{-}^{-}
$$

Here, $y$ is the binary response variable, $x$ is a vector of explanatory variables, $\beta$ is a parameter vector, and $G$ is a function mapping the linear index $x$ ' $\beta$ into the response probability. In our analysis, the response variable, $y$, takes the value one if the respondent has been classified as exhibiting protest behaviour, and zero otherwise. The explanatory variables in $x$ have been chosen on account of a priori expectations of their potential impact on protest behaviour - expectations which are based on economic theory and common sense as well as previous research on protest behaviour. The probit model assumes that the unobservable error terms are normally distributed with mean zero.

\subsection{Variables}

As the aim of the analysis is to establish determinants of protest zero bidding, the dependent variable is a dummy variable (PROT_RESP) taking the value one if the respondent is classified as a protest zero bidder and zero otherwise. Table 2 gives an overview of the descriptive statistics of the dependent variable as well as the explanatory variables that are used in the probit model presented in section 4.

The explanatory variables can roughly be assigned to two structurally different groups: Respondent specific variables which vary for each single respondent, and survey specific variables which vary only across surveys ${ }^{2}$. This distinction is quite important: While we would typically aim to minimize protest behaviour in any SP survey, the respondent specific variables offer only very limited options for the researcher for actively pursuing this objective. However, adjusting the survey according to the survey specific variables is to a much larger extent within the grasp of the researcher. In other terms, if the survey specific variables significantly affect the probability of observing protest behaviour, the researcher can actively adjust the overall design of the survey in order to reduce this

\footnotetext{
${ }^{1}$ Different protest definitions have been used in the surveys - e.g. in some surveys, respondents answering 'don't know' with respect to why they have chosen the status quo alternative are defined as protesters, while this is not the case in other surveys. The issue of different definitions of protest responses is out side the scope of this paper.

${ }^{2}$ Though, in several of the surveys, split samples have been used for testing various methodological issues. This leads to some within-survey variation for the survey specific variables.
} 
probability. In section 4, the explanatory variables and the a priori expectations for these are explained in more detail in conjunction with the discussion of the obtained results.

Table 2. Description of variables

\begin{tabular}{|c|c|c|c|c|}
\hline Variable & Min & Max & Mean & St. d. \\
\hline $\begin{array}{l}\text { PROT_RESP (dummy }=1 \text { if respondent is classified as } \\
\text { protest bidder, } 0 \text { otherwise) }\end{array}$ & 0 & 1 & 0.137 & 0.34 \\
\hline AGE (respondent age) & 16 & 104 & 46.42 & 14.8 \\
\hline GENDER (respondent gender) & 0 & 1 & 0.51 & 0.5 \\
\hline H_INCOME (household income) & 1 & 5 & 4.149 & 1.14 \\
\hline $\begin{array}{l}\text { CHILD (dummy }=1 \text { if one or more children lives in the } \\
\text { household, } 0 \text { otherwise) }\end{array}$ & 0 & 1 & 0.335 & 0.47 \\
\hline $\begin{array}{l}\text { KNOW (dummy }=1 \text { if respondent has relatively more } \\
\text { knowledge about the good than others, } 0 \text { otherwise) }\end{array}$ & 0 & 1 & 0.663 & 0.47 \\
\hline $\begin{array}{l}\text { USE (dummy }=1 \text { if respondent uses the good in } \\
\text { questions, } 0 \text { otherwise) }\end{array}$ & 0 & 1 & 0.611 & 0.49 \\
\hline $\begin{array}{l}\text { MARKET (dummy }=1 \text { if the good being surveyed is a } \\
\text { market good, } 0 \text { otherwise) }\end{array}$ & 0 & 1 & 0.591 & 0.49 \\
\hline $\begin{array}{l}\text { VAL_MET (dummy }=1 \text { if Choice Experiment is used in } \\
\text { the survey, zero if Contingent Valuation) }\end{array}$ & 0 & 1 & 0.76 & 0.43 \\
\hline $\begin{array}{l}\text { OE_OTHER (dummy }=1 \text { if an open ended format is } \\
\text { used, } 0 \text { otherwise) }\end{array}$ & 0 & 1 & 0.192 & 0.39 \\
\hline $\begin{array}{l}\text { NO_WORDS (Number of words in scenario } \\
\text { description preceding the valuation questions) }\end{array}$ & 175 & 1666 & 596.7 & 400 \\
\hline $\begin{array}{l}\text { PV_TAX (dummy }=1 \text { if tax is used as payment vehicle, } \\
0 \text { otherwise) }\end{array}$ & 0 & 1 & 0.232 & 0.42 \\
\hline $\begin{array}{l}\text { NO_DESIG (Number of alternatives in full factorial } \\
\text { design) }\end{array}$ & 0 & 4374 & 249.3 & 879 \\
\hline $\begin{array}{l}\text { REM_CT (dummy=1 if Cheap Talk reminder is used, } 0 \\
\text { otherwise) }\end{array}$ & 0 & 1 & 0.872 & 0.33 \\
\hline $\begin{array}{l}\text { REM_OOR (dummy=1 if Opt-Out reminder is used, } 0 \\
\text { otherwise) }\end{array}$ & 0 & 1 & 0.599 & 0.49 \\
\hline
\end{tabular}

Note: Total number of respondents is 22,049 


\section{Expectations and results}

The results obtained using the binary probit model is displayed in table 3 below. The model which is based on 22,049 observations from 10 different surveys obtains a McFadden's adjusted pseudo- $\mathrm{R}^{2}$ of 0.148 . This indicates that the specified model describes the variation in the data reasonably well (Domencich and McFadden 1975; Louviere et al. 2000). Besides reporting parameter estimates and significance levels, table 3 also reports the average partial effects (APE) evaluated at the means of the explanatory variables. The APE serves as measure of the magnitude of the variable's impact on the probability of observing protest behaviour.

Table 3. Binary probit model describing the determinants of protest behaviour

\begin{tabular}{|c|c|c|c|c|}
\hline Parameter & Estimate & & t-value & APE at means \\
\hline Constant & 0.3129 & $* *$ & 2.60 & 0.0580 \\
\hline AGE & 0.0097 & $* * *$ & 11.35 & 0.0018 \\
\hline GENDER & 0.0036 & & 0.15 & 0.0007 \\
\hline H_INCOME & -0.0209 & $*$ & -1.98 & -0.0039 \\
\hline CHILD & 0.1141 & $* * *$ & 4.24 & 0.0216 \\
\hline KNOW & -0.1934 & $* * *$ & -5.90 & -0.0373 \\
\hline USE & 0.0287 & & 1.03 & 0.0053 \\
\hline MARKET & -0.5964 & $* * *$ & -7.14 & -0.1187 \\
\hline VAL_MET & -0.5583 & $* * *$ & -9.52 & -0.1228 \\
\hline OE_OTHER & 0.2144 & $* * *$ & 3.88 & 0.0430 \\
\hline NO_WORDS & -0.0007 & $* * *$ & -13.14 & -0.0001 \\
\hline PV_TAX & -0.4178 & $* * *$ & -6.99 & -0.0673 \\
\hline NO_DESIG & $2.30 \mathrm{E}-06$ & & 0.16 & $4.26 \mathrm{E}-07$ \\
\hline REM_CT & -0.7877 & $* * *$ & -11.01 & -0.2003 \\
\hline REM_OOR & 0.1971 & $* *$ & 2.88 & 0.0357 \\
\hline Number of observations & 22049 & & & \\
\hline Log Likelihood at convergence & -7487 & & & \\
\hline McFadden's adj. pseudo- $\mathrm{R}^{2}$ & 0.148 & & & \\
\hline
\end{tabular}

Note: '*' indicates significance at $5 \%$ level; '**' at $1 \%$ level; and '***' at $0.1 \%$ level 


\subsection{Respondent specific variables}

\subsubsection{Age}

The respondent's age typically exhibits a negative relationship with stated value in SP surveys (Carson et al. 2001). Thus, it seems reasonable to expect a positive relationship between the age and the probability of protest behaviour, as the probability of protest behaviour increases when more respondents report a zero bid in the valuation question(s). Answering a valuation questions typically constitutes a cognitively demanding task. If mental capacity reduces as you get older, a heuristic to cope with such difficult tasks could be to state a protest zero bid. Furthermore, younger people are often thought of as being more open-minded, which might be a prerequisite for respondents to accept the hypothetical scenario. Meyerhoff and Liebe (2009) establish a link between protesting and the likelihood of choosing a status quo alternative (i.e. a zero bid) in CE. Moreover, it has been found that increasing age leads to increasing probability of choosing the status quo alternative (von Haefen et al. 2005). This is also in support of the expectation of a positive relationship between age and the probability of protest behaviour. The results in table 3 are in support of this expectation. Increasing age has a highly significant and positive influence on the likelihood of observing a protest response.

\subsubsection{Gender}

Several studies have found gender differences in WTP, see e.g. Dupont (2004), Brown and Taylor 2000, Berrens et al. (1997). Considering this, it does not seem farfetched to conjecture that protest behaviour might differ across gender. Mitani and Flores (2007) and Ladenburg and Olsen (2008) find evidence that biases in SP surveys may impact differently across gender. One explanation is that females are comprehensive information processors whereas males are much more selective when processing information (Meyers-Levy 1989). Thus, if male respondents tend not to read the information, they might lack some information which could help them answer the valuation question. If a respondent has not actually read all the information that is provided, then answering the valuation question may become even more difficult than it inherently already is. Stating a protest bid could be an easy and quick way out of such a (to some extent self-inflicted) difficult valuation question. Hence we might expect that males will exhibit a higher tendency to protest. Turning to the results in table 3 , this expectation is not met. The GENDER parameter estimate is not significantly different from zero. Hence, our data does not exhibit any gender differences with regard to protest behaviour when all the other variables in the model are accounted for.

\subsubsection{Household income}

Income typically exhibits a positive relationship with stated values in SP surveys (Carson et al. 2001). This is in accordance with economic theory which would also prescribe that low income groups should have a higher propensity to state a zero WTP bid than high income groups. We might expect that some of the zero bidders feel a need to justify their zero bids with other reasons than inability to pay, simply because they think that they ought to pay (especially for the non-market goods). Another reason might be that they are 
affected by some normative social influence in terms of others expecting them to pay (Kelman 1958). If such a compliance conformity effect is indeed present, then zero bidders who would like to follow the social norm even though they have decided to bid zero might feel inclined to state reasons other than simple budget restraints ${ }^{3}$.

Consequently, we might hypothesize that increasing income would reduce the propensity to protest bid. The significantly negative H_INCOME parameter estimate in table 3 supports this hypothesis. This suggests that there is indeed a general tendency for lower income groups to be more likely to exhibit protest behaviour than higher income groups.

\subsubsection{Children in the household}

There is some evidence in the literature that the number of children in the household affect the stated values in SP surveys at least when the surveys consider environmental goods (Teal and Loomis 2000). Specifically, it has been found that parents tend to state higher WTP than their childless counterparts (Dupont 2004). Thus, based on arguments similar to those above, we might expect that parents are less likely to state a protest response. However, table 3 shows the opposite to be the case. Respondents with children in their household exhibit a significantly higher likelihood of protest behaviour than those without children in the household. One explanation could be found in the timeframe of the choice tasks. Parents might have a tighter time schedule than respondents without children, and because of that they could be "tempted" to use the heuristics of always choosing status quo when completing the choice tasks more often then their counterparts. On the other hand, it might be argued that parents with a very tight time schedule would refrain from even responding to the survey in the first place.

\subsubsection{Knowledge about the good}

The level of knowledge and experience with a good has often been found to affect stated values in SP surveys. List (2003) and Cherry et al. (2003) find that stated values become more consistent with true preferences as market experience increases through a process of repetition and learning ${ }^{4}$. Bateman et al. (2004) further underline the importance of knowledge and experience, specifically in relation to learning effects in SP surveys. The fact that learning effects are important for respondents to be able to state their true WTP implies that the initial level of knowledge of and experience with the good in question is insufficient for respondents to make fully informed and rational choices. Thus, we might

\footnotetext{
${ }^{3}$ Typically, conformity effects in SP surveys are thought of as affecting positive bids in terms of respondents adjusting their own WTP statements relative to the WTP statements of others (Alpizar et al. 2008). The situation we describe here would be a sort of second best conformity effect: Due to budget constraints, the zero bidders have already decided not to conform to the social norm which would be to state a positive bid. However, they might think that stating budget constraints as the reason for a zero bid might make others think less of them, and, hence, they pick some other reason. Choosing a protest reason indicates that a zero bid might not be the respondent's true WTP. In that sense, this could be a way of signaling that you might conform to the social norm of paying for the good, but you just do not conform to the premises of the survey.

${ }^{4}$ Of course, market experience and knowledge is strictly speaking two different concepts. Especially in non-market good cases it is evident that one can have relatively good knowledge of the good without having any market experience. Both concepts are however clearly related to learning.
} 
conjecture that the likelihood of observing protest behaviour is affected by the respondent's initial level of knowledge about the good. Specifically, we might expect a low level of knowledge to lead to a relatively higher propensity of displaying protest behaviour. In order to test for this, we constructed the KNOW variable on the basis of questions relating to the respondents knowledge about the good in question ${ }^{5}$. The results of the probit model in table 3 reveals that increased knowledge does indeed reduce the likelihood of a protest response.

\subsubsection{Use of the good}

A positive relationship is typically expected between the use of a good and the stated values for the good (Carson et al. 2001; Bateman et al. 2002). Of course, if considering a good that contains mainly non-use values, e.g. protection of animal species in remote or non-accessible areas, this relationship becomes less relevant. However, for all the surveys in the present meta-study there are clear elements of use values associated with the goods being surveyed. Thus, it has been possible to construct a user-variable (USE) based on survey questions concerning the respondents' use of the good. According to the typically observed positive relationship between use and WTP, we would expect users of a good to exhibit a lower probability of protesting than non-users. However somewhat surprisingly, table 3 reveals that whether the respondent has been classified as a user or a non-user of the good in question has no significant impact on the probability of observing protest behaviour. Thus, our data suggests that there is no clear-cut relationship between use and protest behaviour.

\subsection{Survey specific variables}

\subsubsection{Market versus non-market goods}

In the valuation literature on market versus non-market goods it is found that the issue of hypothetical bias is reduced when the market good is valued (Hanemann 1991). One may hypothesise that the extent to which such bias (as well as other biases) is prevalent depends on context, and may be less of a problem if preferences are better formed. On a rather general level, Hanley et al. (1997) note that respondents often find it relatively difficult to answer WTP questions when they have no prior experience of trading with the good in question. As previously argued, respondent might resort to the heuristic of stating a protest answer in such a situation. Brookshire et al. (1982) have looked at the issue in the context of embedding, and these authors suggest that in cases where private purchase is conceivable, it is not so likely that embedding occurs because the respondents have experience in determining their WTP through their daily shopping. In contrast to the variable KNOW, which captures the effect of individual respondents relative knowledge of the good, this variable (MARKET) detains the effect of whether or not the good being

\footnotetext{
${ }^{5}$ For each of the ten dataset, questions were identified which could serve as indicators of the respondents level of knowledge about the good. Due to the varying goods and questions in the different surveys, the specification of the KNOW variable is based to some extent on subjective judgments concerning what constitutes a high level of knowledge. Even so, the basic function of this variable is to divide the sample into two groups; one with relatively higher level of knowledge than the other.
} 
valued is a market or a non-market good. That being said the argumentation for our expectation of the sign of this variable follows what is mentioned above and in section 4.1.5. On the basis of this we expect the MARKET variable to have negative effect on the probability of a protest answer. The results concerning the MARKET variable in table 3 confirms our expectation. The effect of the good in question being a market good rather than a non-market good is a significantly negative impact on the propensity to state a protest answer.

\subsubsection{Choice Experiment versus Contingent Valuation Method}

Only one study to date has explicitly analysed whether the number of respondents who hold protest beliefs or who give protest responses significantly differs between $\mathrm{CV}$ and CE (Meyerhoff \& Liebe 2008). They find no clear pattern of differences between CE and $\mathrm{CV}$, with respect to the rate of protest answers. On this basis, we might expect to find no effect of the VAL_MET variable in the present analysis. Other more general statements have been made claiming that $\mathrm{CE}$ generates a lower number of protest responses. For example, Mogas et al. (2005) argue that the lower response rate they observed in their $\mathrm{CV}$ compared to their $\mathrm{CE}$ was due to a 'protest motive' in $\mathrm{CV}$. It may be argued that $\mathrm{CE}$ reduces strategic behaviour due to the $\mathrm{CE}$ method being less 'transparent' than the $\mathrm{CV}$ method (Hanley et al. 1998a; Hanley et al. 1998b). One could hypothesise that the same pattern would exist with respect to protest answers, thus a reduction in protest answers when using $\mathrm{CE}$ instead of the $\mathrm{CV}$ method would be expected. Additionally, the repeated choice nature of $\mathrm{CE}$ might add to this expectation in the sense that the more times respondents are asked to choose, the higher the likelihood that the respondent at some point decides to choose a non-status-quo alternative for instance due to a feeling of moral obligation. The parameter estimate for the VAL_MET variable confirms this hypothesis. When using the CE method instead of the CV method, the probability of observing a protest answer is significantly reduced.

\subsubsection{Open ended versus closed ended format}

It has been argued that using an open ended rather than a dichotomous choice WTP question format places a more difficult cognitive burden on respondents (Hanley 1997). In their recommendations regarding the use of CVM, the NOAA panel presents two arguments for using the dichotomous choice approach rather than the open ended approach (Arrow et al. 1993). First of all, they argue that open ended question scenario descriptions are less realistic than those of dichotomous choice questions, as people in their everyday life are more used to deciding whether or not to accept a given price for a good than coming up with a figure themselves. As previously argued, a heuristic out of a difficult choice might be to state a protest answer. Based on this, we might expect to find increased probability of protesting in studies using open ended WTP questions. Secondly, the NOAA panel argues that open ended questions are more prone to strategic behaviour than dichotomous choice questions. It is less clear what effect we might expect from the choice of question format on protest behaviour based on this. In their seminal book on the CVM methodology, Mitchell \& Carson (1989) argue that open ended question formats generally obtain higher non-response rates and higher percentage of protest-zeros than closed ended formats. Based on this, it is not surprising that our model returns a 
significantly positive parameter estimate for the OE_OTHER variable. This implies that using an open ended WTP question format rather than other formats will ceteris paribus increase the probability of obtaining protest responses.

\subsubsection{Length of the scenario description}

As stated above in section 4.1.5 respondents' knowledge of a good is expected to reduce the likelihood of a protest response, which is shown also to be the case in the present meta-study. If we assume that the length of the scenario description is a factor describing the amount of information provided to the respondents, long descriptions equals more information. Concerning information provision and WTP, studies have shown that increased amount of information leads to increased WTP (see e.g. Mørkbak \& Nordström 2009). Thus, under the assumption of the length of the scenario description being positive correlated with the amount of information provided, our ex ante expectation of the variable NO_WORDS is that it will contribute with a negative effect on the likelihood of a protest response. On the other hand the length of the scenario description could be argued to affect the cognitive burden for the respondents. Turning to the literature on questionnaire research, meta-analyses suggest that longer mail questionnaires are associated with lower response rates (Heberlein \& Baumgartner 1978; Yammarino et al. 1991), whereas there are found no significant effect on the response rate of the length of web-based questionnaires (Cook et al. 2000; Sheehan 2001). Based on these observations, one could argue that due to an increased cognitive burden, respondents are more often likely to become protesters when presented to long scenario descriptions. The results from the probit model in Table 3 show that the number of words in the scenario description has a negative effect on the likelihood of protest responses.

\subsubsection{Using tax as a payment vehicle}

Mitchell and Carson (1989) argue that the choice of payment vehicle should be expected to influence WTP amounts. In the CV literature Kontoleon et al. (2005) found no differences in WTP for genetically modified foods when using tax and fee as payment vehicles respectively, while Hayes et al. (1992) found that the WTP for improved water quality was larger when using tax as payment vehicle as opposed to a fee payment.

However, with respect to the response rate, Hayes et al. (1992) found that it decreased with $33 \%$, when using a fee payment instead of a tax payment. Finally Daubert \& Young (1981) found that using taxes as payment vehicle opposed to using entrance fee increased the number of protest bidders. As this shows, there is no clear evidence of either taxes or fees resulting in increasing or reducing protest responses, but the only study examining the effect of choice of payment vehicle on the rate of protest responses finds a reduced protest response rate associated with an entrance fee vehicle opposed to a tax payment vehicle (Daubert \& Young 1981). With this in mind our ex antes expectations to the tax payment vehicle variable PV_TAX is that it should have a positive influence on the likelihood of a protest response. As can be seen from the table, this is not the case - the variable for using tax as a payment vehicle is significant and negative, suggesting that by using tax as the payment vehicle, the number of protest responses is reduced. An explanation on this could be that the countries where these surveys all have been 
conducted, are countries where the use of taxes are very common tools, when financing new policy schemes.

\subsubsection{Dimension of the experimental design as related to cognitive complexity}

As mentioned above, the cognitive complexity of the valuation task might affect the observed propensity to protest. If indeed there is a gap between the cognitive capability of the respondent and the difficulty of the valuation question (the "C-D gap" suggested by Heiner (1983)), again, respondents may simplify their decisions by using decision heuristics (Simon 1955; Kahneman et al. 1982). If such decision strategies are invoked, the answers to the valuation questions might not reflect the true preferences of the respondent and the implication might be that observed behaviour is inconsistent with optimization of a Neo- classical utility function (Kahneman \& Tversky 1979; Mazzotta \& Opaluch 1995). Several decision heuristics have been mentioned in the literature (Loewenstein 2001; Svenson 1979). In relation to the present paper, one relevant decision heuristic to consider is that of eliminating a subset of alternatives from the valuation task (Mazzotta \& Opaluch 1995). In CE surveys this might result in the respondent consistently choosing the status quo alternative through the entire sequence of choice sets, and then in the follow-up questions stating a protest reason for doing so. One wellknown proxy of complexity/difficulty in CE is the dimension of the design (Bateman et al. 2002). The larger the number of attributes and attribute levels used in the survey, the larger the experimental design will need to be. This implies first of all that the choice sets become relatively more complex to evaluate, and, secondly, that the respondent has to evaluate more of them (Arentze et al. 2003). This potentially causes a C-D gap which, as argued above, could increase the probability of obtaining protest answers. However, the non-significance of the parameter estimate for the variable describing the number of alternatives in the full factorial design (NO_DESIG) in table 3 cannot confirm this. One explanation might be that there are other significant variables in the model that are more or less describing the effect of complexity as will be discussed in section 4 below. Hence, the results suggest that when accounting for other factors related to complexity, the size of the experimental design does not affect the probability of obtaining protest answers.

\subsubsection{Using Cheap Talk}

Cummings and Taylor (1999) introduced the "Cheap Talk" reminder (CT) which basically explains the problem of hypothetical bias to respondents prior to the preference elicitation. In three independent contingent valuation surveys they found CT to reduce stated WTP and thus effectively reduce the hypothetical bias. However, the effect of CT has been tested extensively in subsequent CVM and CE studies, and the results here are more ambiguous. Aadland and Caplan (2003), List (2001) and Lusk (2003) find that CT only influences the preferences of specific sub-groups. Samnaliev et al. (2003) and Carlsson and Martinsson (2006) do not find CT to effectively reduce WTP, and Aadland and Caplan (2006) even find that the CT increases WTP. Carlsson et al. (2005) and List et al. (2006) both use relatively short CT scripts in CE surveys and find evidence that CT reduces hypothetical bias to some extent. However, in List et al. (2006) CT seems to decrease the internal consistency of respondents' preferences. In Carlsson et al. (2005) 7 
out of 10 attributes were valued significantly lesser with a CT script provided than without one. In a more recent study, Carlsson et al. (2008) find CT to be ineffective in a CE survey. With respect to protest bidders, Ami et al. (2009) show that cheap talk has a differentiated effect depending on the scenario implemented. It decreases protest responses with no effect on WTP values in a scenario based on a new drug. When a move to a less polluted city is the context, it has no effect on protest responses but decreases WTP values, and finally, cheap talk increases protest responses but decreases WTP values when new regional air pollution regulations are at stake. Following the previous analogy used with respect to protest responses and WTP - decreasing WTP implies larger rate of zero-bidders, which again imply larger possibility of protest responses, the ex ante expectations of the cheap talk variable in the present study is that if a cheap talk script is included in the survey, we would expect that it would increase the possibility of a protest response. However, if one sees the cheap talk script as making the whole CE exercise more realistic, we would expect that the script would produce more valid zero-bidders, hence reduce the number of protesters. Whether it is the first or the second argument that holds is difficult to predict, but the results from table 3 shows that when there is a cheap talk script included in the survey (REM_CT), the likelihood of a protest response is indeed reduced.

\subsubsection{Using Opt-Out Reminder}

In a CE context, Ladenburg \& Olsen (2009) introduce a so-called Opt-Out Reminder. This is a short script simply instructing respondents to choose the zero-priced option, i.e. the status quo option, if they find the non-zero-priced experimentally designed alternatives in a choice set too expensive. The OOR is displayed just before each single choice set to account for the repeated choice nature of CE. The purpose of the OOR is to augment and improve the effectiveness of Cheap Talk scripts in terms of their ability to reduce hypothetical bias. Ladenburg \& Olsen find no increase in protest zero bidding even though a significant increase in the propensity to choose the opt-out is observed as a consequence of introducing the OOR. Rather than generalizing based on results from a single survey, Ladenburg \& Olsen calls for further validation of their results. Hence, the REM_OOR variable is included in the present analysis to validate that the OOR does not increase protest behaviour among respondents. The a priori expectation was that the REM_OOR variable would have no significant influence on the probability of protesting. However, somewhat discouraging for the OOR, our results indicate that when controlling for a number of other factors, the reminder actually has a significantly positive effect on the probability of observing protest behaviour. In other words, by using an OOR one might increase the number of protest responses.

\section{Discussion and conclusion}

If the distribution of protest responses is not independent of respondent demographics, the elicitation method, the question format, etc., then simply expelling protesters from surveys will lead to sample selection issues, but also WTP results will not be comparable across surveys (Jorgensen et al. 1999). Our results suggest that some of the differences in WTP typically observed between different demographic groups, different elicitation 
formats and different question formats might actually be attributed to inherent differences in the propensity to protest. Specifically, our results show that the propensity for respondents to exhibit protest behaviour when asked a stated preference type valuation question depends on a number of factors, individual-specific as well as survey-specific.

Individual-specific factors influencing the propensity to protest are generally beyond the influence of the researcher. However, there are possible countermeasures against such external factors leading to for instance sample selectivity problems when omitting protest responses from analysis. One such is the use of protest reduction entreaties as suggested by for instance Bonnichsen and Ladenburg (2009) among others. They find that entreaties clearly instructing respondents that the payments in the SP survey are purely hypothetical are able to reduce the number of protesters significantly. In relation to the individual-specific variables affecting the propensity to protest identified in the present survey, such entreaties might be targeted directly at respondents with a relatively higher risk of protesting, i.e. older people, low income groups, people with children, and people with relatively little knowledge of the good. Internet surveys would offer the opportunity to identify these groups of respondents prior to the preference eliciting questions and maybe subject them to an entreaty. Additionally, another way of reducing protest behaviour in a survey would seem to be by making sure that respondents have a generally high level of knowledge about the good in question. Again, respondents with relatively low levels of knowledge might be identified in initial screening questions and accordingly subjected to additional information.

For the survey-specific factors, which are much more controllable to the researcher, we find a number of interesting results which might be used in order to reduce the impact of protest behaviour. First and foremost, our results suggest that if the researcher chooses to use CVM rather than $\mathrm{CE}$, this decision entails a higher rate of protesters, ceteris paribus. Additionally, if the CVM is conducted using open ended question format rather than dichotomous choice, the number of protesters will be even larger. The average partial effects estimates presented in table 3 reveals that these two decisions have a large impact on the probability of obtaining protest responses. Furthermore, if the good under consideration is a non-marketed good, the probability of protesting increases drastically. Of course, whether a survey considers a market or a non-market good is somewhat out of the hands of the researcher. Typically, some external demand for valuation of a specific good will be the driver of a survey, and in that case the character of the good is given. The implications are that especially in the non-market good cases researcher should be aware that using CE rather than open ended CVM presents a way of significantly reducing the impact of protest behaviour.

When it comes to the actual construction and setting up of questionnaires to be used for SP surveys, our results indicate that researchers can reduce the risk of obtaining protest responses in a number of ways. In the description of the hypothetical scenario, it seems that the length of the scenario as measured by the number of words can be considered. Even though the impact is not large, there is a significant tendency that the longer the scenario, the lower the amount of protesters. The obvious interpretation here would be that information is important to respondents. It is a well-known fact that one should 
generally aim to keep questionnaires as short as possible (Dillman 2007). In case of information overload, some respondents might not read all the information available (Meyers-Levy 1989). Hence, researcher might want to keep their scenario descriptions short. Our results underline that this entails a risk of increasing the number of protesters slightly. However, considering the relatively small impact, this may be an acceptable price to pay in order to ensure that respondents have actually read and assimilated all the available information in the scenario description which might be necessary in order to answer the valuation questions. Another element of the scenario description is the use of reminders. Our results show that the OOR increases protest behaviour which is clearly an undesirable feature. However, the OOR is intended to be used in conjunction with CT which has a much larger negative impact on the probability of observing protest responses according to the average partial effects reported in table 3 . If the OOR indeed helps reducing hypothetical bias as intended, a slightly increased share of protesters, and associated loss of efficiency might be a price worth paying to obtain more realistic WTP estimates. Finally, the choice of payment vehicle needs to be considered. As the brief literature review shows, there is no clear evidence of either taxes or fees resulting in increasing or reducing protest responses. However, the results in present paper show that by using tax as the payment vehicle, the number of protest responses is indeed reduced. One should though carefully note that this result may be quit dependent upon respondents' familiarity with tax payments in general.

An element which is present to some degree in several of the variables is complexity. At the survey level, the MARKET, VAL_MET, OE_OTHER, NO_WORDS and NO_DESIG variables are clearly to some extent associated with the effect of complexity and cognitive burden entailed in the valuation question(s) ${ }^{6}$. At the respondent level, at least the KNOW variable and possibly also the H_INCOME variable ${ }^{7}$ are related to complexity and cognitive capability issues. Not surprisingly, the general picture is that increasing complexity entails increasing probability of obtaining protest answers. Hence, another way of reducing protest behaviour would be to reduce the complexity of the survey, e.g. by using CE or, providing sufficiently long scenario descriptions and generally trying to increase the respondent's level of knowledge prior to the preference eliciting choice sets.

While the current study provides some useful practical bearings and guidelines for researchers wishing to reduce the number of protesters in future studies, we should note that the results to some extent are preliminary as we plan to extent our database with additional datasets in order to get more variation with respect to the survey specific variables. Furthermore, there are still important and unanswered questions deserving attention in future research. One important question relates to the definition of protest responses. As Jorgensen et al. (1999) note there appears to be no generally agreed upon protocol describing what constitutes a protest response, let alone whether protest responses should be attributed only to zero-bids or also to the positive bids. The present meta-study exemplifies this as several different approaches to protest response

\footnotetext{
${ }^{6}$ Indeed, correlation analysis revealed some correlations among these variables.

${ }^{7}$ H_INCOME is correlated with educational level which arguably to some extent reflects the cognitive capability of the respondent.
} 
classification have been used in the single surveys from which the data used in the analysis originate. It would be beneficial in future studies to examine to what extent the current findings depend on the definition of protesters. As long as censoring of protest responses is the common approach, comparison of results from different surveys would strictly speaking only make sense if identical protest definitions are used. 


\section{References}

Aadland D, Caplan AJ (2003): Willingness to pay for curbside recycling with detection and mitigation of hypothetical bias. American Journal Agricultural Economics, 85(2):492-502.

Aadland D \& Caplan AJ (2006): Cheap talk reconsidered: New evidence from CVM. Journal of Economic Behavior and Organisation, 60(4):562-578.

Alpizar, F., F. Carlsson and O. Johansson-Stenman (2008): Anonymity, reciprocity, and conformity: Evidence from voluntary contributions to a national park in Costa Rica, Journal of Public Economics 92, 1047-1060

Ami, D., Aprahamian, F., Chanel, O., \& Luchini, S. (2009): A Test of Cheap Talk in Different Hypothetical Contexts: The Case of Air Pollution. Document de Travail NO. 2009-09, Universités d'Aix-Marseille II et III.

Arentze, T., Borgers, A., Timmermans, H., \& DelMistro, R. (2003): Transport stated choice responses: effects of task complexity, presentation format and literacy,

Transportation Research Part E: Logistics and Transportation Review, vol. 39, no. 3, pp. 229-244.

Arrow, K., R. Solow, P. R. Portney, E. E. Leamer, R. Radner, \& H. Schuman (1993):

Report of the NOAA Panel on Contingent Valuation The National Ocean and Atmospheric Association's Damage Assessment and Restoration Program (DARP), Washington, USA.

Bateman, I., B. Day, D. Dupont, S. Georgiou, J. Louviere, S. Morimoto, P. Wang (2004): Preference formation in choice experiments $(C E)$ : task awareness and learning in the cognitive process, in: Thirteenth Annual Conference of the European Association of Environmental and Resource Economists (EAERE), June 2004.

Bateman, I., R. T. Carson, B. Day, M. Hanemann, N. Hanley, T. Hett, M. Jones-Lee, G. Loomes, S. Mourato, E. Özdemiroglu, D. W. Pearce, R. Sugden, \& J. Swanson (2002): Economic Valuation with Stated Preference Techniques - A Manual Edward Elgar, Cheltenham, UK

Berrens, R. P., Bohara, A. K., \& Kerkvliet, J. (1997): A Randomized Response Approach to Dichotomous Choice Contingent Valuation, American Journal of Agricultural Economics, vol. 79, no. 1, pp. 252-266

Bonnichsen, Ole og Jacob Ladenburg (2009): Using an Ex-ante Entreatry to Reduce Protest Zero Bias in Stated Preference Surveys A Health Economic Case. Journal of Choice Modelling, 2(2):83-98. 
Boyle, K. J., 2003. Contingent Valuation in Practice. In: P. A. Champ, K. J. Boyle and T. C. Brown, A Primer on Nonmarket Valuation. Kluwer, Dordrecht

Brookshire, D. S.; Thayer, M. A.; Schulze, W. D. \& d'Arge, R. C. (1982): Valuing Public Goods: A Comparison of Survey and Hedonic Approaches, American Economic Review, vol. 72, no. 1, pp. 165-177.

Brown, K. M. \& Taylor, L. O. (2000): Do as you say, say as you do: evidence on gender differences in actual and stated contributions to public goods, Journal of Economic Behavior \& Organization, vol. 43, no. 1, pp. 127-139

Carlsson F, Frykblom P, Lagerkvist CJ (2005): Using cheap talk as a test of validity in choice experiments. Economic Letters, 89(2):147-152.

Carlsson F \& Martinsson P (2006): Do experience and cheap talk influence willingness to pay in an open-ended contingent valuation survey. Working Papers in Economics no.

190. Dept. of Econ., School of Business, Economics and Law, University of Gothenburg.

Carlsson F, Daruvala D, Jaldell H (2008): Do you do what you say or do you do what you say others do? Working Papers in Economics No. 309. Department of Economics, University of Gothenburg.

Carson, R. T., Flores, N. E., \& Meade, N. F. (2001): Contingent Valuation: Controversies and Evidence, Environmental and Resource Economics, vol. 19, no. 2, pp. 173-210.

Cherry, T. L., Crocker, T. D., \& Shogren, J. F. (2003): Rationality spillovers, Journal of Environmental Economics and Management, vol. 45, no. 1, pp. 63-84

Christoffersen, L. B. (2006). "Juvre meadow - an economic analysis". Report from FOI, University of Copenhagen, Denmark.

Cook, C., Heath, F., \& Thompson, R.L. (2000): A Meta-Analysis of Response Rates in Web- or Internet-Based Surveys. Educational and Psychological Measurement 60: 821836.

Cummings RG, Taylor LO (1999): Unbiased value estimates for environmental goods: A cheap talk design for the contingent valuation method. American Economic Review, 89(3):649-665.

Daubert, J.T. \& Young, R.A. (1981): Recreational Demands for Maintaining Instream Flows: A Contingent Valuation Approach. American Journal of Agricultural Economics, vol 63(4): 666-676.

Dillman, D. A. (2007): Mail and Internet Surveys : The Tailored Design Method - 2007 Update with New Internet, Visual, and Mixed-Mode Guide Second edn, John Wiley \& Sons Inc, New York. 
Domencich, T. \& D. McFadden (1975): Urban Travel Demand: A Behavioral Analysis North-Holland Publishing Company, Amsterdam.

Dupont, D. P. (2004): Do children matter? An examination of gender differences in environmental valuation, Ecological Economics, vol. 49, no. 3, pp. 273-286

Hanemann, M. (1991): Willingness to Pay and Willingness to Accept: How Much Can They Differ? The American Economic Review, vol. 81, no. 3, pp. 635-647.

Hanley, N., J. F. Shogren, \& B. White (1997): Environmental Economics in Theory and Practice Palgrave Macmillan, England.

Hanley, N., Macmillan, D. C., Wright, R. E., Bullock, C., Simpson, I., Parsisson, D., \& Crabtree, B. (1998a): Contingent Valuation Versus Choice Experiments: Estimating the Benefits of Environmentally Sensitive Areas in Scotland, Journal of Agricultural Economics, vol. 49, no. 1, pp. 1-15

Hanley, N., Wright, R. E., \& Adamowicz, W. L. (1998b): Using Choice Experiments to Value the Environment, Environmental and Resource Economics, vol. 11, no. 3-4, pp. 413-428.

Hartje, V., I. Meyer and J. Meyerhoff (2002): Kosten einer möglichen Klimaveränderung auf Sylt. In Daschkeit, A., Schottes, P., (eds.), Sylt - Klimafolgen für Mensch und Küste. Berlin, 181-218.

Hayes, K.M., Tyrrell, T.J., \& Anderson, G. (1992): Estimating the Benefits of Water Quality Improvements in the Upper Narragansett Bay. Marine Resource Economics, vol. 7: 75-85.

Heberlein, T.A. \& Baumgartner, R. (1979): Factors Affecting Response Rates to Mailed Questionnaires: A Quantitative Analysis of the Published Literature. American Sociological Review. 43: 447-62.

Heiner, R. A. (1983): The Origin of Predictable Behavior, The American Economic Review, vol. 47, no. 4, pp. 560-595.

Jensen, C.L., Nissen, C.J., Olsen, S.B. \& Boesen, M. (2010): Analyse af udenlandske fisketurister i Danmark (An analysis of tourists angling in Denmark - In Danish only). Working paper from FOI, University of Copenhagen, Denmark. (Forthcoming)

Jorgensen, B. S., Syme, G. J., Bishop, B. J., \& Nancarrow, B. E. (1999): Protest Responses in Contingent Valuation, Environmental and Resource Economics, vol. 14, no. 1, pp. 131-150

Jorgensen, B. S. \& Syme, G. J., 2000. Protest Response and Willingness to Pay: Attitude toward Paying for Stormwater Pollution Abatment. Ecological Economics. 33: 251-265. 
Jorgensen, B. S., Wilson, M. A. \& Heberlein, T. A., 2001. Fairness in the Contingent Valuation of Environmental Goods: Attitude Toward Paying for Environmental Improvements at Two Levels of Scope. Ecological Economics. 36: 133-148.

Kahneman, D. \& Tversky, A. (1979): Prospect Theory: An analysis of Decision under Risk, Econometrica, vol. 47, no. 2, pp. 263-291.

Kahneman, D., P. Slovic, \& A. Tversky (1982): Judgement Under Uncertainty: Heuristics and Biases Cambridge University Press, New York.

Kelman, H. (1958): Compliance, identification, and internalization: Three processes of attitude change. Journal of Conflict Resolution, 1, 51-60.

Kontoleon, A., Yabe, M., \& Darby, L. (2005): Alternative Payment Vehicles in Contingent Valuation: The Case of Genetically Modified Foods. MPRA Paper No. 1827, University of Cambridge, UK. http://mpra.ub.uni-muenchen.de/1827/.

Ladenburg, J. \& Olsen, S.B. (2009): Augmenting short Cheap Talk scripts with a repeated Opt-Out Reminder in Choice Experiment surveys. Paper presented at the EAERE 2009 Annual Conference, Amsterdam, Holland 24-27 June, 2009.

Ladenburg, J. \& Olsen, S. B. (2008): Gender-specific starting point bias in choice experiments: Evidence from an empirical study, Journal of Environmental Economics and Management, vol. 56, no. 3, pp. 275-285

List JA (2001): Do explicit warnings eliminate the hypothetical bias in elicitation procedures? Evidence from field auctions for sportscards. American Economic Review, 91(3):1498-1507.

List, J. A. (2003): Does Market Experience Eliminate Market Anomalies? Quarterly Journal of Economics, vol. 118, no. 1, pp. 41-71.

List JA, Sinha P, Taylor MH (2006): Using choice experiments to value non-market goods and services: Evidence from field experiments. Advances in Economic Analysis and Policy, 6(2):1-37(article 2).

Loewenstein, G. (2001): The Creative Destruction of Decision Research, Journal of Consumer Research, vol. 28, no. 3, pp. 499-505.

Louviere, J., D. A. Hensher, \& J. Swait (2000): Stated Choice Methods. Analysis and Applications University Press, Cambridge, UK

Lusk JL (2003): Effects of cheap talk on consumer willingness-to-pay for golden rice. American Journal Agricultural Economics, 85(4):840-856. 
Mazzotta, M. J. \& Opaluch, J. J. (1995): Decision making when choices are complex: A test of Heiner's hypothesis, Land Economics, vol. 71, no. 4, p. 500.

Meyerhoff, J. \& Liebe, U. (2006): Protest beliefs in contingent valuation: Explaining their motivation, Ecological Economics, vol. 57, no. 4, pp. 583-594.

Meyerhoff, J \& Liebe U. (2008): Do Protest Responses to a Contingent Valuation Question and a Choice Experiment Differ? Environmental and Resource Economics 39 (4): 433-46.

Meyerhoff, J. \& Liebe, U. (2009): Status Quo Effect in Choice Experiments: Empirical Evidence on Attitudes and Choice Task Complexity, Land Economics, vol. 85, no. 3, pp. $515-528$

Meyerhoff, J. \& A. Dehnhardt (2007): The European Water Framework Directive and economic valuation of wetlands: the restoration of floodplains along the River Elbe. European Environment 17(1): 18-36.

Meyers-Levy, J. (1989): Gender differences in information processing: A selective interpretation In: Cognitive and affective responses to advertising, P. Cafferata \& A. M. Tybout, eds., (eds.) (1989): Lexington, MA

Mitani, Y. \& Flores, N. (2007): Does gender matter for demand revelation in threshold public goods experiments? Economic Bulletin, 3(27), 1-7.

Mitchell, R. C. \& R. T. Carson (1989): Using Surveys to Value Public Goods: The Contingent Valuation Method Resources for the Future, Washington D.C., USA

Mogas J, Riera P, Bennett J (2005): Accounting for afforestation externalities: a comparison of contingent valuation and choice modelling. European Environment, 15(1):44-58

Morrison, M. D., Blamey, R. K. \& Bennett, J. W. (2000): Minimising Payment Vehicle Bias in Contingent Valuation Studies. Environmental and Resource Economics. 16: 407422.

Mørkbak, M. R. \& Nordström, J. (2009): The Impact of Information on Consumer Preferences for Different Animal Food Production Methods, Journal of Consumer Policy, vol. DOI 10.1007/s10603-009-9106-9.

Mørkbak, M.R., Christensen, T., Gyrd-Hansen, D. \& Olsen, S.B. (2009): Is Embedding Entailed in Consumer Valuation of Food Safety Characteristics? $113^{\text {th }}$ EAAE Seminar on "A Resilient European Food Industry and Food Chain in a Challenging World" 2009, Crete, Greece.

Nielsen, A. B., Olsen, S. B., \& Lundhede, T. (2007): An economic valuation of the 
recreational benefits associated with nature-based forest management practices, Landscape and Urban Planning, vol. 80, no. 1-2, pp. 63-71

Olsen, S. B., J. Ladenburg, M. L. Petersen, U. Lopdrup, A. S. Hansen, \& A. Dubgaard (2005): Motorways versus Nature - A Welfare Economic Valuation of Impacts. Report from FOI and IMV, Copenhagen.

Samnaliev M, Stevens TH, More T (2003): A comparison of cheap talk and alternative certainty calibration techniques in Contingent Valuation. Working Paper No. 2003-11. Dept. of Res. Econ., University of Massachusetts, Amherst.

Sheehan, K. (2001): E-Mail Survey Response Rates: A Review. Journal of ComputerMediated Communication 6.

Simon, H. A. (1955): A Behavioral Model of Rational Choice, The Quarterly Journal of Economics, vol. 69, no. 1, pp. 99-118.

Strazzera, E., Genius, M., Scarpa, R. \& Hutchinson, W. G. (2003): The Effect of Protest Votes on the Estimates of WTP for Use Values of Recreational Sites. Environmental and Resource Economics. 25: 461-476

Svenson, O. (1979): Process Descriptions of Decision Making. Organizational Behavior and Human Performance 23:86-112

Söderquist, T. (1998): Why Give up Money for the Baltic Sea? Environmental and Resource Economics. 12: 249 - 254

Teal, G. and Loomis, J.B., (2000): Effects of gender and parental status on the economic valuation of increasing wetlands, reducing wildlife contamination and increasing salmon populations. Society and Natural Resources 13 1, pp. 1-14

Tranberg, J., Christoffersen, L.B., Dubgaard, A., Olsen, S.B. \& Lassen, C. (2005): Opfattelse af risiko for oversvømmelse (Perception of the risk of flooding - In Danish only). Report from the Danish Coastal Authority, Lemvig, Denmark.

von Haefen, Roger H., D. Matthew Massey, and Wiktor L. Adamowicz. (2005): Serial Nonparticipation in Repeated Discrete Choice Models. American Journal of Agricultural Economics 87 (4): 1061-76.

Yammarino, F.J., Skinner, S.J., \& Childers, T.L. (1991): Understanding Mail Survey Response Behavior: A Meta-Analysis. Public Opinion Quarterly 55: 613-639. 